\title{
Urbanization can help reduce income inequality
}

\author{
Guanghua Wan ${ }^{1,4}$, Xiaoling Zhang ${ }^{2,3,4 凶}$ and Mengxue Zhao ${ }^{2,3,4}$
}

The global community has been confronted with rising income inequality, in particular, for those least developed countries (LDCs), since the same level of inequality as in advanced countries would push many LDCs into abject poverty. This paper focuses on income inequality in developing countries, particularly LDCs. First, we demonstrate the infeasibility of fiscal measures in resolving income inequality even in developed countries. Second, we show that inequality in LDCs can be largely explained by urban-rural gap. Third, we uncover the benign impacts of urbanization on urban-rural gap. This leads us to propose an out-of-box strategycontaining income inequality by promoting well-managed urbanization. Fourth, we reveal a misperception that may have contributed to the neglect of urban-rural gap in constituting national inequality. This has possibly caused anti-urbanization mentalities and practices, with adverse distributional consequences. Finally, we provide evidence-based policy suggestions aimed at reducing income inequality and poverty - two major goals of SDGs.

npj Urban Sustainability (2022)2:1 ; https://doi.org/10.1038/s42949-021-00040-y

\section{INTRODUCTION}

Income inequality represents one of the most challenging issues confronted by the global community today. Nevertheless, little that is new has been proposed or implemented to tackle worsening distributions prevailing in both developing and developed economies. Even the controversial suggestion of Piketty (2014) to tax assets falls into the conventional wisdom of fiscal measures used to address inequality for thousands of years. The conventional wisdom inevitably involves tax collection and redistribution, both of which have costs and distortions. Most importantly, fiscal resources are always limited, even in the affluent industrialized world, where its effects have been proven insufficient to reverse or contain rising inequality ${ }^{1}$.

It should be stressed that the distributional problem is more urgent and important in developing countries, particularly least developed countries (LDCs). This is because (1) they account for approximately $85 \%$ of the global population; (2) it is simply infeasible for them to allocate enough fiscal resources for redistribution, even in economies with a middle-income level development status. As shown below, on average, upper-middle and high-income countries spent $4.60 \%$ of Gross domestic product (GDP) on social programs in the latest year whereas this percentage is only $1.54 \%$ for other countries; (3) with a lower development status (a smaller pie), a same level of inequality (how the pie is divided) will push many more into abject poverty in developing countries than in developed economies; and (4) worse still, inequality is expected to rise further as the countries take off or continue to grow ${ }^{2,3}$.

Clearly, it is of utmost importance and urgency for developing countries to contain rising inequality, at least for reducing abject poverty, hunger, and malnutrition. Otherwise, the world will risk a further worsening of income distribution, ultimately leading to the failure of Sustainable Development Goals (SDGs) in terms of the first goal of "No Poverty" and the tenth goal of "Reduced Inequalities".

The infeasibility of conventional wisdoms to address the inequality problem appeals for a fundamental rethinking beyond secondary distribution as a major tool for managing income distribution.

This paper focuses on income inequality in developing countries. First, we demonstrate the infeasibility of relying on fiscal transfers to address income inequality. Second, we show that, to a significant extent, inequality in developing countries can be accounted for by the urban-rural gap-an important finding that has attracted little attention to date. Third, we develop a novel technique to discern the benign impacts of urbanization on the urban-rural gap and propose an alternative to the conventional wisdom of fiscal transfers-containing income inequality by promoting well-managed urbanization. Fourth, we point out a misperception that may have contributed to the neglect of the urban-rural gap in measuring national inequality in developing economies. This, as we further argue, has possibly led to antiurbanization mentalities and practices, with adverse distributional consequences. Finally, we conclude with policy suggestions.

\section{RESULTS}

\section{Infeasibility of relying on fiscal measures}

As is well-known, conventional wisdom relies on taxation and fiscal transfers to address income inequality. However, three stylized facts dictate that conventional wisdom will not work effectively. First, developing economies are dominated by informality, implying a narrow taxation base. Second, the small proportion of employees working in formal sectors are not rich (although less poor), meaning that the taxation base is shallow. Finally, the weakness in institutions and governance in LDCs makes both tax collection and fiscal transfers inefficient, with relatively high administrative costs, distortion, and possible corruption.

To demonstrate the infeasibility for most developing countries of relying on fiscal measures to contain income inequality, Fig. 1 plots expenditure on social protection as a share of GDP as well as the urbanization rate against GDP per capita. The plots and fitted lines indicate that both expenditure on social protection and the

\footnotetext{
${ }^{1}$ Institute of World Economy, Fudan University, Shanghai, People's Republic of China. ${ }^{2}$ Department of Public Policy, City University of Hong Kong, Hong Kong, People's Republic of China. ${ }^{3}$ Shenzhen Research Institute, City University of Hong Kong, Shenzhen, People's Republic of China. ${ }^{4}$ These authors contributed equally: Guanghua Wan, Xiaoling Zhang, Mengxue Zhao. ${ }^{凶}$ email: xiaoling.zhang@cityu.edu.hk
} 


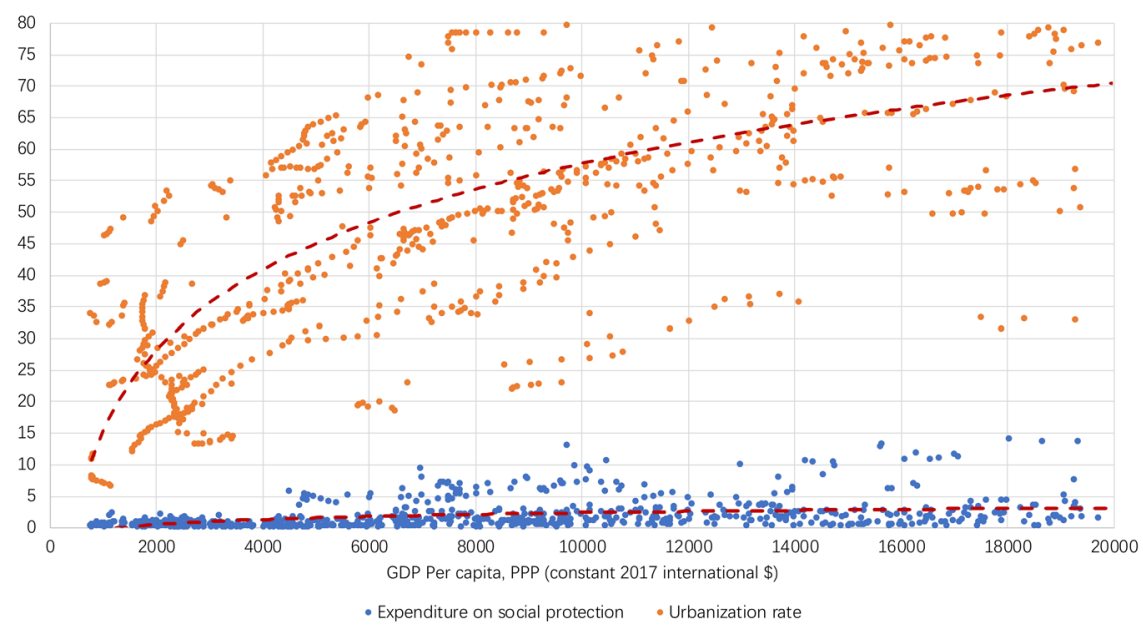

Fig. 1 Expenditure on social protection, urbanization rate, and GDP per capita. This reports the 1990-2017 social protection expenditure and urbanization rate for 100 countries. Notes: (1) The social protection expenditure (\% of GDP) is sourced from the IMF GFS Database. (2) The urbanization rate and GDP per capita are sourced from the WDI Database of the World Bank (2017).
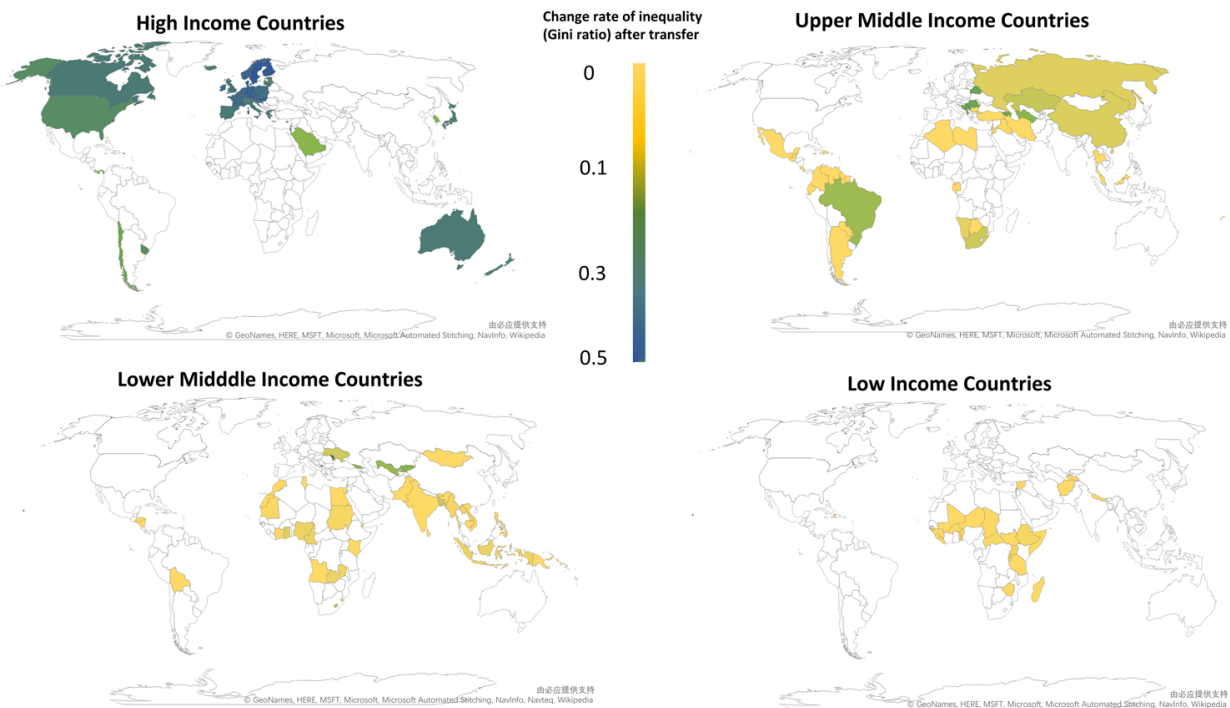

Fig. 2 Impact of redistribution on income inequality. This reports the change rate in the Gini ratios after transfer by country groups in the latest year, showing that fiscal transfers exert little impact on income inequality in developing countries, especially those with a middle or lower development status. Notes: (1) The classification of countries is based on the World Development Report 2017 ${ }^{1}$. (2) Pre-transfer and post-transfer income inequality (Gini ratio) is based on the Standardized World Income Inequality Database (SWIID v7.1) of Solt ${ }^{26}$. (3) The two welfare definitions employed in the SWIID are: (1) market income (pre-tax, pre-transfer income) refers to the amount of money coming into the household, excluding any government cash or near-cash benefits as well as private transfers such as gifts, alimony, or assistance from nonprofit organizations, implying that market measures do not consider any fiscal policies or policies of redistribution; (2) net income (posttax, post-transfer income) is the sum of market income and transfer payments, excluding direct taxes (Solt, 2016) ${ }^{26}$. (4) The change rate of inequality is defined as relative redistribution (market income inequality minus net income inequality, divided by market income inequality). (5) The SWIID maximizes comparability for the broadest possible coverage of countries and years, which is ideal for broadly cross-country research into inequality. Therefore, when calculating the impact of redistribution on income inequality countries of 179 countries, they are comparative due to the same definition of income and transfers.

urbanization rate are positive functions of GDP per capita. In particular, they are quite low in the early stages of development. A low urbanization rate means that the relatively less-poor urbanites represent only a minority of the national population, and only a certain proportion of this minority may be taxed. Meanwhile, it means that most of the population are poor. Further, these taxes must be spent on feeding government employees, defense, the provision of public services, and other essentials. Little can be left for redistribution in LDCs, even in middle-income countries. In other words, it is simply infeasible for some of the less-poor minority of urbanites to help the vast majority of the poor.
To be more specific, Fig. 1 shows that expenditure on social protection is negligible until GDP per capita reaches USD 5000 (2011 PPP-adjusted in constant 2017 international \$). Even for economies with a GDP per capita of USD 5000-10,000, only a small percentage (around 2\%) of GDP was spent on social programs (see Supplementary Table 1). Consequently, redistributions are bound to be insufficient for reducing income inequality, particularly in economies with a middle- or lower-income status.

The impact of social protection on reducing income inequality is more forcefully demonstrated by Fig. 2, where the reduction in the Gini index after fiscal transfer is shown for high-, upper-middle, lower-middle, and low-income countries. Although the impact is 


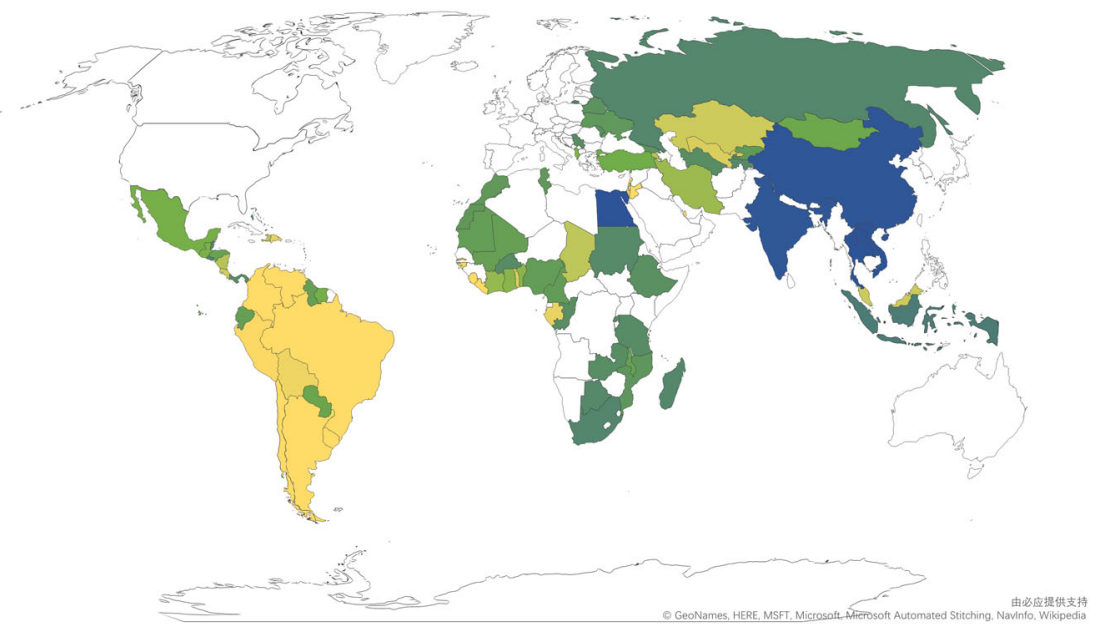

The Share of Urban-Rural Income Gap

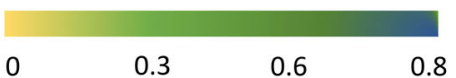

Fig. 3 Contribution of urban-rural gap to national inequality in developing economies. This shows the share of the urban-rural gap in national income inequality in the latest year. Notes: (1) Developed countries are urbanized and thus are not included. (2) National income inequality (the Theil-L index) is converted from the Gini ratios in the Standardized World Income Inequality Database (SWIID v7.1). (3) The urban-rural income gap is estimated by the authors (see methods in the appendix).
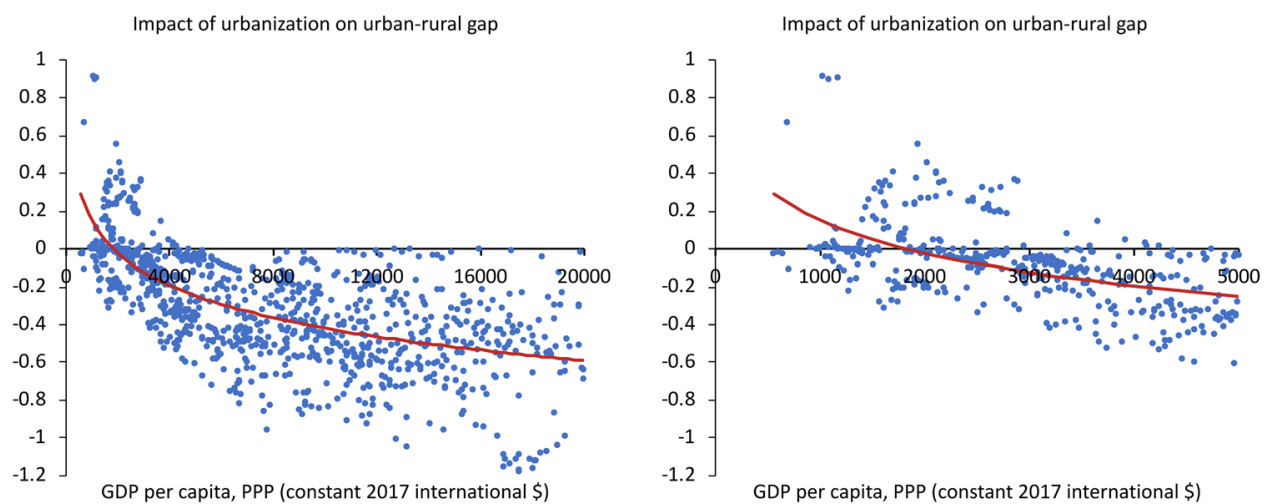

Fig. 4 GDP per capita and the impact of urbanization on the urban-rural gap. This plots the impacts of urbanization on the urban-rural gap using 1990-2017 data from 90 economies. Contrary to our initial expectation, it is surprising to find that urban-rural migration or urbanization before GDP per capita reaches USD 2000 (2011 PPP-adjusted in constant 2017 international \$) leads to an enlargement of the urban-rural gap but the impact of urbanization becomes benign thereafter. Source: Authors' calculations (see Methods).

quite visible for high income and to a less extent upper-middleincome countries, it is quite small for lower-middle-income countries and almost negligible for low-income countries.

\section{Urban-rural gap as a major component of national inequality}

The infeasibility of conventional wisdom established above, together with the importance and urgency of the distributional problem in developing countries (see Introduction), appeal for a fundamental re-thinking. Inspired by Shorrocks and Wan (2005) ${ }^{4}$ and Wan $(2013)^{5}$, as well as the stylized fact that poverty in developing economies is largely a rural phenomenon, our attention turns to the urban-rural gap-an inherent component of national inequality overlooked by Kuznets (1955) and others. Applying the method developed and presented in the Appendix of this paper, Fig. 3 depicts the percentage contribution of the urban-rural gap to national income inequality-showing that the urban-rural gap constitutes a significant component of national inequality. Excluding highly urbanized Latin America, this component amounts to $30 \%$ or more of national inequality. In China, the contribution reaches $50 \%$ or more ${ }^{6}$. As discussed below, this component has been largely overlooked by academia and policy makers. Thus, if the urban-rural gap can be narrowed, national inequality will be much less serious.

To reduce the urban-rural gap, the conventional wisdom relies on fiscal transfers. This, in terms of the formula for computing average income, essentially means a reduction in the numerator for the less-poor urbanites and a corresponding rise in the numerator for the rural poor majority. Given the infeasibility of conventional wisdom discussed earlier, a natural alternative is to reduce/raise the denominators. This implies rural-to-urban migration or urbanization. Urban productivity is generally much higher than its rural counterpart. For example, the former is 4-5 times higher than the latter in Asia ${ }^{7}$. According to Clark (1967)'s law, as the productivity of industry is much higher than agriculture, the labor force must flow from the agricultural sector to the industrial sector, that is, from rural to urban areas. Thus, rural-urban migration or urbanization helps promote growth due to scale, 


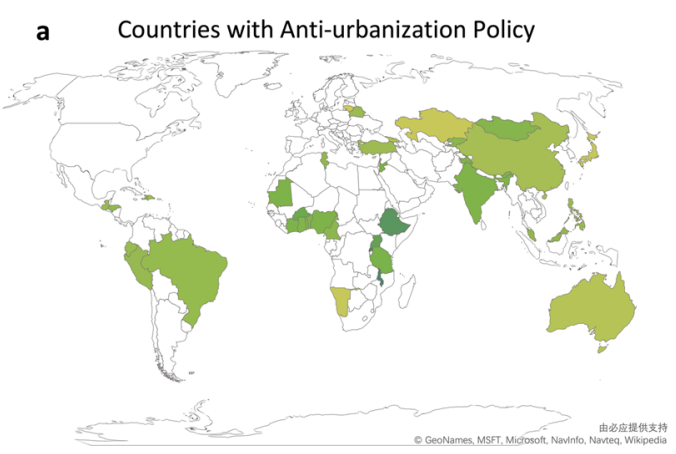

Impact of urbanization on urban-rural income gap b Countries with Pro-urbanization Policy
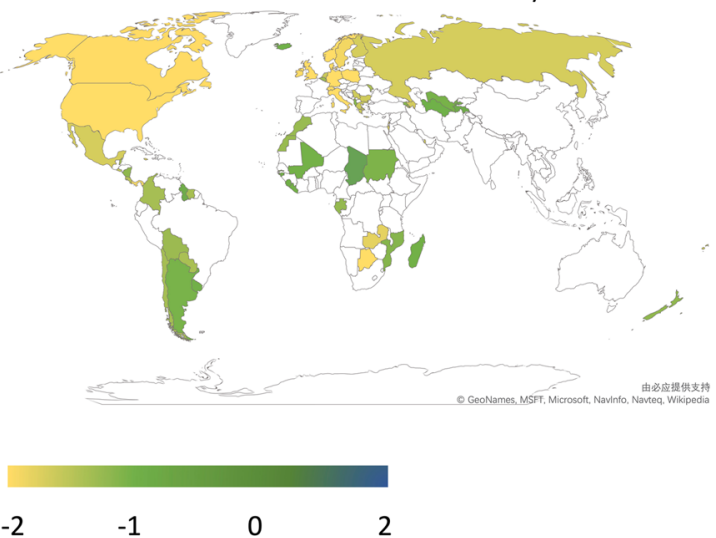

Fig. 5 Urbanization rate and impact of urbanization on the urban-rural gap. This shows that the benign effect kicks in soon after the urbanization rate reaches approximately 30\%. Source: Authors' calculations (see Methods).
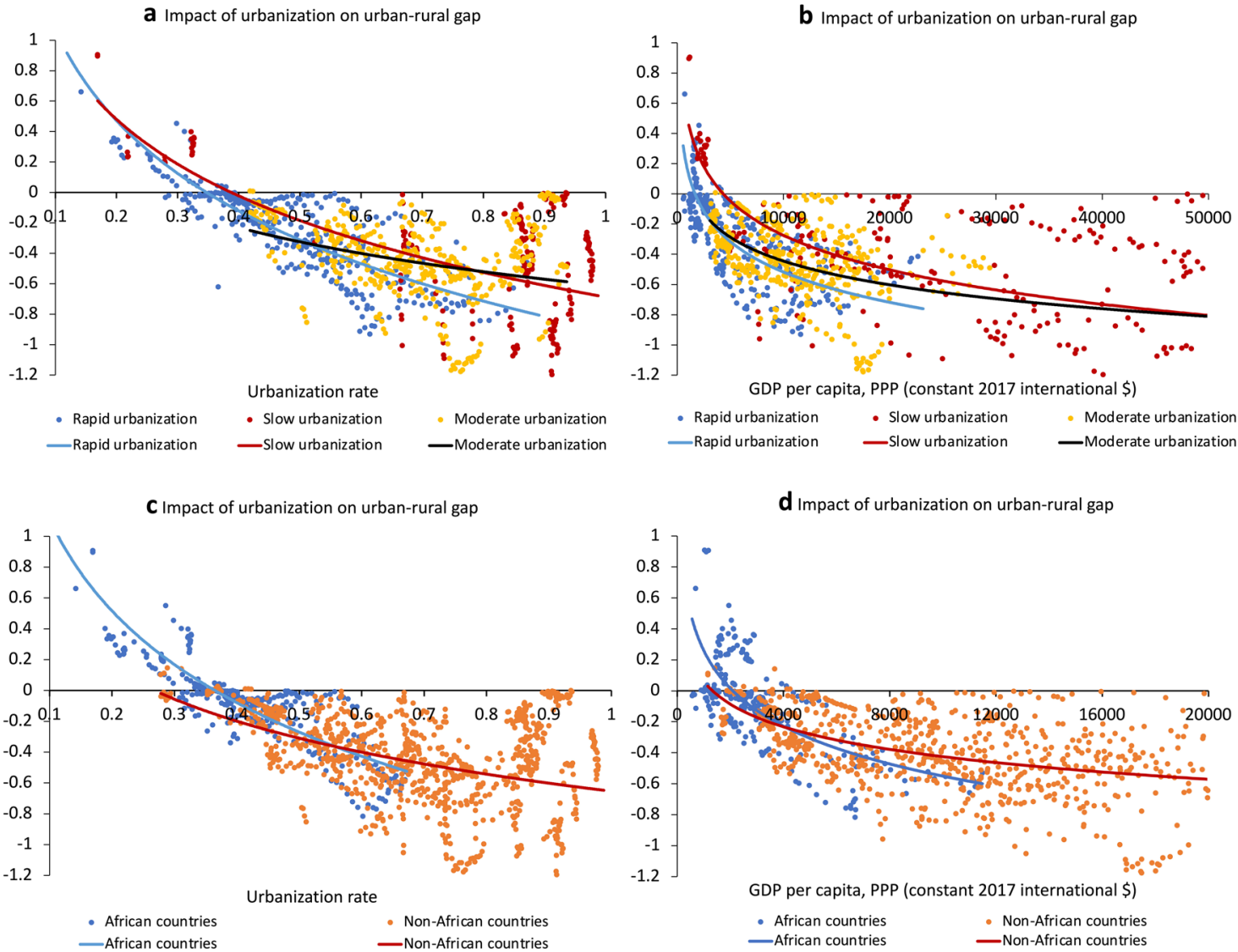

GDP per capita, PPP (constant 2017 international \$)

- African countries $\quad$ - Non-African countries

Fig. 6 Impact of urbanization on the urban-rural gap. a The relationship between urbanization rate and impact of urbanization on urbanrural gap in countries with a different urbanization pace. b The relationship between GDP per capita and impact of urbanization on urbanrural gap in countries with a different urbanization pace. $\mathbf{c}$ The relationship between urbanization rate and impact of urbanization on urbanrural gap in 30 African countries and 60 non-African countries. d The relationship between GDP per capita and impact of urbanization on urban-rural gap in 30 African countries and 60 non-African countries. Note: This plots the marginal impact of urbanization on the urban-rural gap using 1990-2017 data from 90 economies. The pace of urbanization is measured by the growth rate of urbanization (the average annual rate of change of the percentage of urban population). From 1990 to 2017, the median growth rate of urbanization was $1.2 \%$ on the high end in Africa, and $0.2 \%$ on the low end in Europe and Northern America. Here, we define rapid-urbanization, slow-urbanization, and moderateurbanization as having an annual growth rate of urbanization larger than $1.2 \%$, smaller than $0.2 \%$, and between $0.2 \%$ and $1.2 \%$, respectively (UN, 2019 ${ }^{1}$.

location, and agglomeration economies ${ }^{8}$. Meanwhile, according to the Kuznets facts or Clark $(1967)^{9}$, when a country takes off, growth largely occurs in the urban sectors of manufacturing and services, and much less in the rural sector. Consequently, if rural- urban migration lags behind sectoral growth differentials, the urban-rural gap will enlarge. This, ceteris paribus, will lead to a rising national inequality. In contrast, promoting urbanization represents a strategic alternative for developing economies to 
Income gap within urban and rural areas

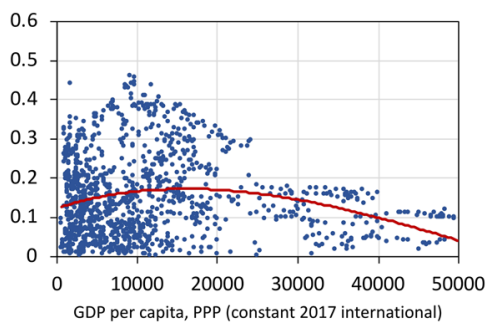

Urban-rural income gap

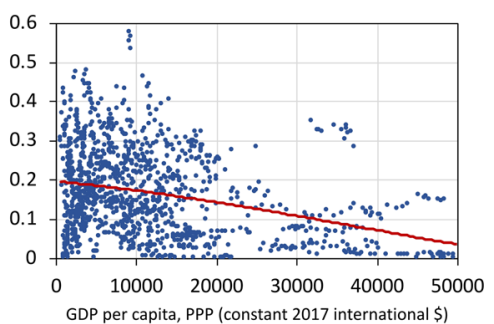

Total income gap

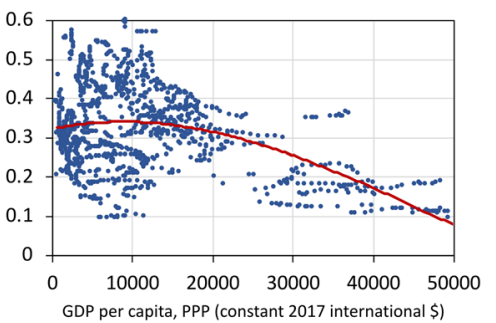

Fig. 7 GDP-Income gap relationship by 90 economies from 1990-2017. Note: This plots the correlations between GDP per capita and income gap using 1990-2017 data from 90 economies.

contain or reduce inequality, entailing the poorer rural residents migrating to cities to share a bigger and faster-growing urban portion of the national pie.

\section{The benign impacts of urbanization on income inequality}

The mechanisms behind which urbanization can help reduce national inequality by narrowing the urban-rural gap include the following.

(1) Alleviating pressures on the resource endowments in the rural area, raising the land/labor ratio. Increases in farm size may also help poor farmers exploit economies of scale in rural production ${ }^{10}$. These help raise rural per capita income.

(2) Generating urban-to-rural remittances, which directly raises rural average income at the cost of its urban counterpart ${ }^{11}$. Indirectly, remittances can also help stimulate the development of non-farming activities in the countryside ${ }^{12}$ and help improve education and health outcomes of rural families ${ }^{13}$. All these contribute to improvements in rural income.

(3) Returning migrants often bring back savings, skills, entrepreneurship, experiences, exposure to urban life, transformed mentality (e.g., motivation, risk-taking attitudes), and even urban connections ${ }^{14}$. They often engage in non-farm activities-helping increase rural income ${ }^{15}$.

Such trends also lead to substantial social connections and closer economic ties between family members of urban migrants $^{16}$. In general, these mechanisms are consistent with the duality theory of Lewis (1954), which holds that development in the industrial or urban sector could benefit the rural poor.

To provide empirical evidence, we use Eq. (2) in the Appendix to estimate the impacts of urbanization on the urban-rural gap in 90 economies. The results in Fig. 4 indicate that urbanization does help reduce national inequality by narrowing the urban-rural gap after GDP per capita reaches USD 2000 (2011 PPP-adjusted in constant 2017 international \$). It is important to point out that, as of 2017, 78 of the 90 economies in our data sample have a GDP per capita greater than USD 2000. In other words, for an absolute majority of countries nowadays, promoting urbanization is expected to help reduce the urban-rural gap and national inequality.

Figure 5 plots the impact of urbanization on the urban-rural gap against the urbanization rate, showing that the benign effect kicks in soon after the urbanization rate reaches approximately $30 \%$. The earlier gap-enlarging effect can be explained by the research finding that early migrants are mostly better off and better educated. Thus, when they migrate, the rural average income will decrease in the short run (see refs. ${ }^{17-19}$ ). In addition, early migrants usually face considerable uncertainties in cities, with which only the capable and educated can $\operatorname{cope}^{20}$. When urbanization reaches a certain level $(\sim 30 \%$ for all countries as shown in Fig. 5 , and $\sim 40 \%$ for African countries in Fig. 7), less educated and less well-off rural residents begin to migrate, helping reduce the urban-rural gap. It should be noted that, out of the 90 economies in our data sample, 81 have already surpassed the $30 \%$ urbanization threshold by 2017 , meaning that developing countries can take advantage of urbanization as a strategy to contain income inequality.

To investigate the possibly heterogeneous impacts of urbanization on the urban-rural gap that are related to urbanization pace, we classify countries as having either rapid-urbanization, moderate-urbanization, or slow-urbanization. As expected, less developed economies with relatively lower levels of urbanization are urbanizing slowly and vice versa. As Fig. $6 \mathrm{a}, \mathrm{b}$ show, the benign impact of urbanization on the urban-rural gap is more significant in rapid-urbanizing countries than in moderate- or slowurbanizing economies. This implies that policies restricting ruralto-urban migration may result in a worsening income distribution. In contrast, well-managed urbanization not only helps reap the benefits of urban agglomeration but also helps reduce inequality, especially in developing countries that are fast urbanizing.

Similarly, to investigate the possibly heterogeneous impacts of urbanization on the urban-rural gap that are related to development levels, we classify countries into African countries and nonAfrican countries. Africa is the least developed continent and most African countries are among the least developed in the world. As of 2017, about one-third of African countries had not reached the urbanization levels of $40 \%$, which is the threshold value of urbanization identified above for making benign impacts on the urban-rural gap. Consequently, urbanization may create a larger urban-rural gap for a small portion of African economies. However, for most African and for almost all non-African countries, urbanization helps reduce their urban-rural gap (see Fig. 6c, d)).

\section{The resulting misperception by the Kuznets hypothesis}

It is important to point out that our proposal is contrary to what the well-known hypothesis of Kuznets (1955) implies. The Kuznets hypothesis depicts an inverted U-shape curve between inequality and industrialization or urbanization, implying urbanization is detrimental to income distribution. However, possibly due to a lack of data, Kuznets (1955) overlooked the urban-rural gap. In essence, his analysis was based on the stylized fact that urban inequality is higher than rural inequality. Consequently, as increasing number of residents migrate from the low-inequality countryside to the high-inequality urban areas, national inequality, defined as the weighted average of urban and rural inequalities, naturally rises. Because the urban-rural gap was overlooked by Kuznets, so are the benign effects of urbanization on national inequality uncovered earlier in this paper.

To illustrate our arguments, Fig. 7 plots total income inequality (right-most plot) and its two components (left-most and middle plots) against GDP per capita. The plots and fitted lines confirm that an inverted U-curve only exists in the relationship between GDP per capita and inequality within urban and rural areas. The urban-rural gap, as an important component of national inequality, declines with GDP per capita. Consequently, when the urbanrural gap is taken into consideration, the Kuznets turning point for 


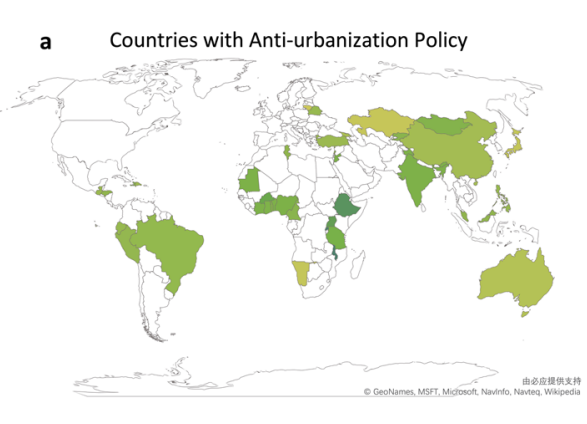

Impact of urbanization on urban-rural income gap

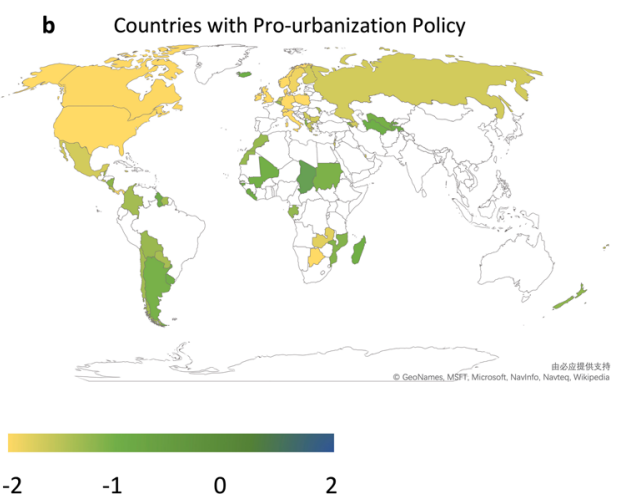

b Countries with Pro-urbanization Policy

Fig. 8 Impacts of urbanization on the urban-rural gap for country groups with different urbanization policies. a Country group with antiurbanization policy. b Country group with pro-urbanization policy. This shows the impacts of urbanization on the urban-rural gap for 90 economies in 2015. Clearly, the benign impacts are more significant in countries with a pro-urbanization policy. Notes: (1) Country grouping is based on "Policies on Spatial Distribution and Urbanization" published by the United Nations in 2016. Anti-urbanization is defined as the decentralization of large urban centers to smaller urban, suburban, or rural areas. The counter process is defined as pro-urbanization policy. (2) The impact of urbanization on the urban-rural gap is calculated by the authors (see Methods).
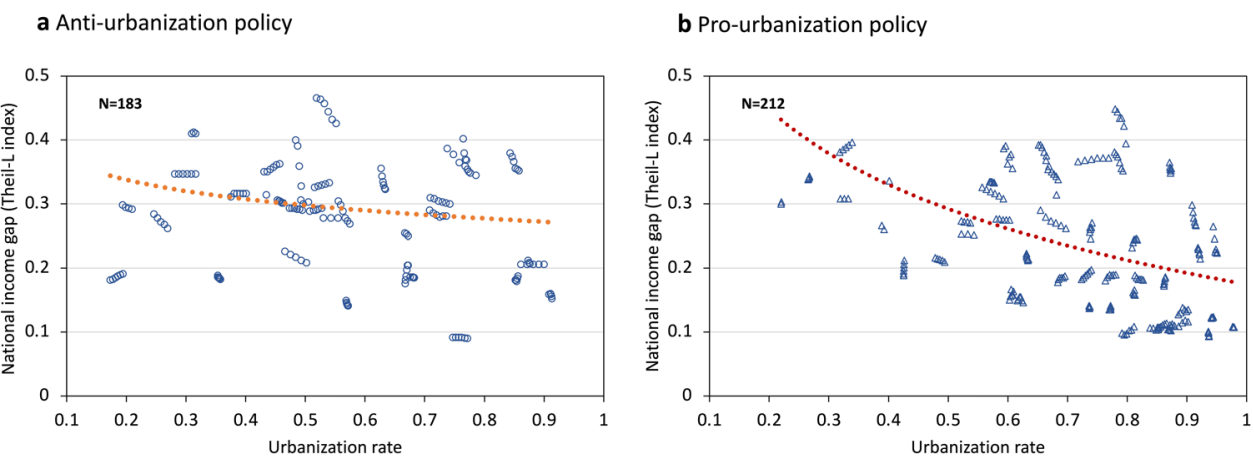

Fig. 9 Impact of urbanization on national income inequality by country groups with different urbanization policies. a Country group with anti-urbanization policy. b Country group with pro-urbanization policy. This further examines how urbanization policies affect national income inequality. The plots are based on data from 90 economies for the period of 2011-2015 and indicate that pro-urbanization countries have a larger benign impact of urbanization on national income inequality. Notes: (1) Country grouping is based on "Policies on Spatial Distribution and Urbanization" published by the United Nations in 2016. Anti-urbanization is defined as the decentralization of large urban centers to smaller urban, suburban, or rural areas. The counter process is defined as pro-urbanization policy. (2) National income inequality is calculated by the authors (see Methods).

the total income inequality would come earlier since the urbanrural gap can be reduced through urbanization.

Given the prominence and popularity of Kuznets (1955), the unqualified positive association between urbanization and inequality may have contributed to the perception that urbanization has an adverse effect on income distribution, potentially leading to many developing economies an anti-urbanization mentality, including policy makers in developing countries. As Quigley $(2008)^{21}$ noted, two thirds of national governments in the developing world are unsupportive of urbanization. This naturally would lead to a slowdown in urbanization, with adverse growth and distributional consequences.

To investigate if differences in government attitudes towards urbanization are correlated with income inequality, we use UN (2016)'s $s^{22}$ report, which classifies countries as either pro- or an anti-urbanization. Figure 8 plots the marginal impacts of urbanization on the urban-rural gap for the two groups, confirming that the impacts are more significant in countries with pro-urbanization policies.

To quantify the differences in the impacts of urbanization on national inequality caused by different policy stances, we regress the estimated Theil index-which measures national inequalityon a dummy variable representing different government attitudes, while controlling for other variables. The results confirm that shifting from an anti- to pro-urbanization policy stance leads to an $\sim 30 \%$ increase in the benign effect of urbanization on national inequality (see Fig. 9 and Supplementary Table 1).

\section{DISCUSSION}

This paper intends to advance our understanding of the relationship between urbanization and income inequality. Starting with the infeasibility of relying on fiscal measures, we reveal the benign role of urbanization in containing the urban-rural gap-a major component of national income inequality. This benign effect has been largely neglected to date. Our conclusion is simple and profound: well-managed urbanization can lead to a win-win outcome (growth with equality).

Our key finding that urbanization helps reduce the urban-rural gap after GDP reaches a relatively low level of USD 3000 (2011 PPP-adjusted in constant 2017 international \$) has profound implications. Developing economies, which in general are facing increasingly serious distributional challenges, can take urbanization as a feasible and effective strategy for containing income inequality. The current anti-urbanization mindset and practices in some developing countries need to be reversed to achieve a winwin rather than a loss-loss outcome in terms of both efficiency and equity. Taking African countries with the fastest rates of urbanization as an example, the decentralization of services in Ghana leads to a reducing rural-to-urban migration ${ }^{23}$ 
(the Ethiopian government directly discourages rural-to-urban migration; National Population Policy of Ethiopia, 1993) ${ }^{24}$; and urban registration cards are required for new migrants' employment in the formal sector and to access services in African cities ${ }^{25}$. These mindsets and practices that have been generating adverse real-life consequences may have been derived from the conventional perception in developing economies that urbanization is positively correlated with income inequality-an unfortunate misinterpretation of the well-known Kuznets hypothesis. In his Noble prize-winning paper, Kuznets (1955) did not consider the urban-rural gap, which is a major component of national inequality, possibly due to lack of data.

The profound policy implications outlined above appeal for more research as well as the policy attention of national governments and the international development community to promote well-managed urbanization. Such research and policy actions are expected to help improve the social welfare and the wellbeing of ordinary citizens in developing countries, particularly the rural poor. This, in turn, would aid the ascertainment of SDGs.

More concretely, policy makers at different levels of government need to take a pro-active stance on urbanization by facilitating rural-urban migration and the provision of basic services to migrant workers and families. These include setting minimum-wage standard for migrant workers, prioritizing job creation in urban development, and utilizing big data and the internet to provide employment information to new migrants. Sufficient consideration needs to be given to recent migrants when designing and implementing public housing, health, education, and job-training programs (see Supplementary Table 1). If a migrant worker is unable to find suitable employment in a city, he or she will move back home or move to another city. Thus, in the short-term, the top priority of governments is to help migrant workers find suitable employment. The concrete measures could include providing employment information to new migrants and job-training programs. Furthermore, migrant workers are mostly concentrated in informal sectors in urban areas with low pay and little social protection. Hence, in the long-term, the emphasis of government endeavors should be on reducing living costs and providing better protection for migrant workers, including the enforcement of minimum-wage regulations, and the equal access to affordable housing, education, and healthcare. Migrants need to have equal rights in the context of community development and other policy decisions. International organizations such as UN-Habitat could play a significant role by promoting the exchange of good policies and practices in migration and urban development.

There are unresolved theoretical issues, appealing for work from the research community. For example, it remains unknown if, and how, urbanization leads to a rising income inequality within cities. What are the measures that can prevent or minimize the clustering of poor migrants or formation of slums? Despite industrialization being good for job creation and poverty alleviation, the cause-effect relationship between urbanization and industrialization requires further research attention.

\section{METHODS}

\section{Decomposition of income inequality}

To formally examine the role of urbanization in addressing the inequality issue, the well-known Theil-L index, denoted by $T$, is used to measure inequality. Conceptually, national inequality consists of three components of rural inequality $\left(T_{r}\right)$, urban inequality $\left(T_{u}\right)$, and the urban-rural gap. As argued by Shorrocks and Wan (2005), a major advantage of the Theil-L index is that it entails expressing national inequality as the sum of the three components just mentioned:

$$
\begin{aligned}
T & =\left[W_{r} T_{r}+W_{u} T_{u}\right]+\left[W_{r} \ln \left(W_{r}+W_{u} Y_{u} / Y_{r}\right)+W_{u} \ln \left(W_{u}+W_{r} Y_{r} / Y_{u}\right)\right] \\
& =[\text { within rural inequality }+ \text { within urban inequality }]+[\text { urban-rural gap }] \\
& =[\text { within component/inequality }]+[\text { between component/urban-rural gap }] \\
& =A+B
\end{aligned}
$$

where subscripts $u$ and $r$ index urban and rural sectors, $W$ denotes population share that are used as weights in Eq. (1), $Y$ denotes average income. By definition, $W_{u}+W_{r}=1$.

\section{The impact of urbanization on income inequality}

Since urban population share is equivalent to the urbanization rate, the marginal impact of urbanization on national inequality can be easily derived as:

$$
\begin{aligned}
\frac{\partial T}{\partial W_{u}} & =\left[T_{u}-T_{r}\right]+\left[\left(\ln Y_{r}-\ln Y_{u}\right)+\left(Y_{u}-Y_{r}\right) / Y\right] \\
& =[\operatorname{lmpact} \text { on the within component }]+[\operatorname{lmpact} \text { on the gap }] \\
& =A^{*}+B^{*}
\end{aligned}
$$

Since it is a stylized fact that $T_{u}>T_{r}, \mathrm{~A}^{*}>0$. Thus, if the second term $\mathrm{B}^{*}$ in (2) is neglected as Kuznets (1955) did, it must have lent support to the misperception that urbanization or industrialization leads to rising inequality. Further, since $Y_{u}>Y_{r}$ generally, the impact of urbanization on the urban-rural gap is uncertain, as $\ln \left(Y_{r} / Y_{u}\right)<0$ but $\left(Y_{u}-Y_{r}\right) / Y>0$.

To empirically implement (1) and (2) requires data for $T_{u}, T_{r}, W_{u}, Y_{u}$, and $Y_{r}$. Wu represents the urbanization rate and is available from WDI, $Y_{u}$ and $Y_{r}$ are average GDP for rural and urban residents and can be broadly estimated as $Y_{r}=$ Agricultural GDP/rural population and $Y_{u}=$ Non-agricultural GDP/urban population.. All GDP data are available from WDI, along with population data. Thus, both $B$ and $B^{*}$ can be easily obtained.

The challenge lies at estimating $A^{*}=T_{u}-T_{r}$. The national inequality $T$ can be sourced from the SWIID database of Solt ${ }^{26}$, which provides Gini estimates. The Gini estimates can be converted to $T$ under the reasonable assumption of a lognormal distribution of income (see ref. ${ }^{27}$ ).

$T=\left[\Phi^{1}\left(\frac{\text { Gini }+1}{2}\right)\right]^{2}$

Rearranging (1) yields:

$T-B=\left(1-W_{u}\right) T_{r}+W_{u} T_{u}$

Note that the within-urban and within-rural inequalities $T_{u}$ and $T_{r}$ change slowly over time. Therefore, Eq. (4) can be used to solve the two unknowns of $T_{r}$ and $T_{u}$ using adjacent observations for $T, B$, and $W_{u}$.

\section{Relationship between urbanization policy and inequality}

To estimate the impact of urbanization policy stance on national inequality, we use the regression model:

$$
\begin{aligned}
\text { Inequality }_{i, t}= & \beta_{0}+\beta_{1} \text { Wuit }+\beta_{2} \text { Policy }_{i t}+\beta_{3}\left(W u_{i t} U r_{i t} \times \text { Policy }_{i t}\right) \\
& +\beta_{4} \operatorname{InGDP}_{i t}+\beta_{5}\left(\operatorname{InGDP}_{i t}\right)^{2}+\sum a_{j} X_{i t}+\gamma_{i}+\delta_{t}+\varepsilon_{i t}
\end{aligned}
$$

where $i$ and $t$ indicate country and year respectively, Inequality represents national income inequality measured by the Theil-L index, Wuit represents the urbanization rate, and GDP represents GDP per capita. Here Policy is a dummy variable, which equals 1 for economies with a pro-urbanization policy stance and 0 otherwise. The classification of policy stance can be obtained from "Policies on Spatial Distribution and Urbanization" published by the United Nations in 2016. $X$ is a set of control variables, including economic openness measured by FDI and trade volume as percentages of GDP, government interventions measured by government expense as a percentage of GDP, and redistribution policies measured by tax revenue as a percentage of GDP. $\gamma_{i}$ and $\delta_{t}$ are the country fixed effects and year fixed effect respectively, and $\varepsilon_{i t}$ is the error term. The partial effect of urbanization on national inequality is given by $\left(\beta_{1}+\beta_{3}\right.$ Policy $\left.y_{i t}\right)$. The interaction term $\left(W u_{i t} \times\right.$ Policy $\left.y_{i t}\right)$ measures the moderating effect of urbanization policy stance on the urbanization-inequality relationship.

\section{DATA AVAILABILITY}

Observations on the Gini estimates are collected from the Standardized World Income Inequality Database (SWIID v7.1). (Source: Solt, Frederick. 2016. 
"The Standardized World Income Inequality Database." Social Science Quarterly 97. SWIID Version 7.1, August 2018). To assess the impact of urbanization on the urbanrural gap, these Gini estimates are converted into the Theil index-another popular measure of inequality (see Methods). The decomposition of national inequality was conducted by the authors (see Methods). Here, we report 90 economies. Data for per capita GDP (2011 PPP-adjusted in constant 2017 international \$) are from the Word Bank Database (2017). Social protection spending data are from the IMF GFS Database (available at: data.imf.org [June 2017]).

Received: 23 April 2021; Accepted: 26 October 2021; Published online: 10 January 2022

\section{REFERENCES}

1. Piketty, T. Capital in the Twenty-First Century. (Harvard University Press, 2018).

2. Kuznets, S. Economic growth and income inequality. Am. Econ. Rev. 45, 1-28 (1955).

3. Lewis, W. A. Economic development with unlimited supplies of labour. Manch. Sch. 22, 139-191 (1954).

4. Shorrocks, A. \& Wan, G. Spatial decomposition of inequality. J. Econ. Geogr. 5, 59-81 (2005).

5. Guanghua, W. The urbanization-inequality nexus: method and application to China. Econ. Res. J. 5, 73-86 (2013).

6. Wan, G., Lu, M. \& Chen, Z. Globalization and regional income inequality: empirical evidence from within China. Rev. Income Wealth 53, 35-59 (2007).

7. Asian Development Bank. Key indicators for Asia and the Pacific. (2012).

8. Glaeser, E. L. Cities, Agglomeration, and Spatial Equilibrium. (Oxford University Press, 2008).

9. Clark, C. The Conditions of Economic Progress. (Macmillan, London, 1967).

10. $\mathrm{Wu}, \mathrm{Y}$. et al. Policy distortions, farm size, and the overuse of agricultural chemicals in China. Proc. Natl Acad. Sci. USA 115, 7010-7015 (2018).

11. Lall, S. V. \& Selod, H. Rural-Urban Migration in Developing Countries: A Survey of Theoretical Predictions and Empirical Findings. Vol. 3915 (World Bank Publications, 2006).

12. Klugman, J. Human development report 2009. Overcoming barriers: Human mobility and development. Overcoming Barriers: Human Mobility and Development (October 5, 2009). (UNDP-HDRO Human Development Reports, 2009).

13. Becker, C. M. Urbanization and Rural-Urban Migration. In International Handbook of Development Economics, (eds. Dutt, K. A. \& Ros, J.), vols 1 \& 2, chapter 35, (Edward Elgar Publishing, 2008).

14. Kilic, T., Carletto, C., Davis, B. \& Zezza, A. Investing back home Return migration and business ownership in Albania 1. Econ. Trans. 17, 587-623 (2009).

15. Bouahom, B., Douangsavanh, L. \& Rigg, J. Building sustainable livelihoods in Laos: untangling farm from non-farm, progress from distress. Geoforum 35, 607-619 (2004).

16. Yusoff, N. Urbanization in Northern Corridor Economic Region in Malaysia. (BoD-Books on Demand, 2019).

17. Simmons, A. B. \& Ramiro, C. G. Rural—urban migration: who comes, who stays, who returns? The Case of Bogotá, Columbia, 1929-1968. Int. Migr. Rev. 6, 166-181 (1972).

18. Lipton, M. Migration from rural areas of poor countries: the impact on rural productivity and income distribution. World Dev. 8, 1-24 (1980).

19. Fang, C., Yang, D. \& Meiyan, W. Migration and Labor Mobility in China. Human Development Research Papers (2009 to present) HDRP-2009-09 (2009).

20. Cai, F., Wang, D. \& Du, Y. Regional disparity and economic growth in China: the impact of labor market distortions. China Econ. Rev. 13, 197-212 (2002).

21. Quigley, J. M. Urbanization, Agglomeration, and Economic Development. Commission on Growth and Development Working Paper; No. 19. (World Bank, Washington, DC, 2008).
22. UN. Population Division. Policies on Spatial Distribution and Urbanization: Data Booklet (ST/ESA/ SER.A/394). (2016).

23. Owusu, G. Small towns in Ghana: justifications for their promotion under Ghana's decentralisation programme. African Stud. Quar. 8, 48-69 (2005).

24. Office of the Prime Minister. National Population Policy of Ethiopia. (Office of the Prime Minister, 1993).

25. Ruhiiga, T. Urbanisation in South Africa: a critical review of policy, planning and practice. Afr Popul. Stud. 28, 610-622 (2014).

26. Solt, F. The Standardized World Income Inequality Database. Soc. Sci. Quar. 97, 1267-1281 (2016).

27. Wan, G., Wang, C. \& Zhang, X. The Poverty-Growth-Inequality Triangle: Asia 1960s to 2010s. Soc. Indic. Res. 153, 795-822 (2021)

\section{ACKNOWLEDGEMENTS}

We appreciate the funding support from the National Natural Science Foundation of China (NSF grants 71833003 and 71834005).

\section{AUTHOR CONTRIBUTIONS}

G.H.W. and X.L.Z. designed the research. X.L.Z. and M.X.Z. compiled the data. G.H.W., X.L.Z. and M.X.Z. carried out the statistical analysis. G.H.W. and X.L.Z. led the writing of the paper with substantial input from M.X.Z.

\section{COMPETING INTERESTS}

X.Z. is the Associate Editor of NPJ Urban Sustainability. Other authors declare that they have no other competing interests.

\section{ADDITIONAL INFORMATION}

Supplementary information The online version contains supplementary material available at https://doi.org/10.1038/s42949-021-00040-y.

Correspondence and requests for materials should be addressed to Xiaoling Zhang.

Reprints and permission information is available at http://www.nature.com/ reprints

Publisher's note Springer Nature remains neutral with regard to jurisdictional claims in published maps and institutional affiliations.

\section{(i)}

Open Access This article is licensed under a Creative Commons Attribution 4.0 International License, which permits use, sharing, adaptation, distribution and reproduction in any medium or format, as long as you give appropriate credit to the original author(s) and the source, provide a link to the Creative Commons license, and indicate if changes were made. The images or other third party material in this article are included in the article's Creative Commons license, unless indicated otherwise in a credit line to the material. If material is not included in the article's Creative Commons license and your intended use is not permitted by statutory regulation or exceeds the permitted use, you will need to obtain permission directly from the copyright holder. To view a copy of this license, visit http://creativecommons. org/licenses/by/4.0/.

(c) The Author(s) 2022 